\title{
AVALIAÇÃO NUTRICIONAL DE UMA DIETA SUPLEMENTADA COM MULTIMISTURA: ESTUDO EM RATOS ${ }^{1}$
}

\author{
Marta Suely MADRUGA ${ }^{2, *}$, Hosana Bandeira SANTOS ${ }^{3}$, Francisca Martins BION ${ }^{4}$,
}

\author{
Norma Lúcia Marinho ANTUNES ${ }^{4}$
}

\begin{abstract}
RESUMO
Foi realizado estudo utilizando-se 60 ratos machos Wistar, com o objetivo de avaliar a influência de uma multimistura no combate à desnutrição. Todos os ratos foram submetidos a 14 dias de depleção, após este período, 12 ratos foram selecionados para formar o Grupo 0 ou Aprotéico; o restante foi distribuído em 4 grupos: I - dieta controle; II - dieta creche; III - dieta creche mais 1,2g de Multimistura e IV - dieta creche mais 2,4g de multimistura. A multimistura constituía-se por 47,5\% de fubá de milho; 47,5\% de farelo de trigo; 4\% de pó de sementes de melão, gergelim, abóbora e amendoim; 0,5\% de pó da folha da mandioca e 0,5\% do pó da casca de ovo. A composição centesimal da multimistura reportou elevados teores de carboidratos $(74,24 \%)$ e proteínas (11,75\%). A multimistura apresentou em sua composição mineral 8,07\% de ferro; 357,45mg\% de cálcio; 235,10mg\% de magnésio; $677,65 \%$ de potássio; $570,21 \mathrm{mg} \%$ de fósforo e $7,02 \mathrm{mg} \%$ de sódio. No ensaio biológico, observou-se que o Grupo I - controle - obteve um ganho de peso corporal de $42 \%$ mais elevado que os Grupos II e III e 37\% a mais que o Grupo IV. As ingestões alimentar e protéica foram superiores no Grupo I. Observou-se que o acréscimo de multimistura não influenciou na recuperação ponderal dos ratos.
\end{abstract}

Palavras-chave: multimistura; desnutrição; ratos Wistar; composição centesimal.

\section{SUMMARY}

NUTRITIONAL EVALUATION OF A DIET SUPPLEMENT WITH "MULTIMISTURA": STUDY WITH RATS. A study was developed with 60 Wistar male rats, aiming to evaluate the influence of a "multimistura" against malnutrition. All animals were submitted to 14 days of malnutrition, and after this period, 12 rats were selected to constitute group "O" or non-protein; the others were distributed among 4 groups: I - control diet of casein; II - crèche diet; III - crèche diet plus $1,2 \mathrm{~g}$ of multimistura; IV - crèche diet plus $2.4 \mathrm{~g}$ of "multimistura". The "multimistura" was formulated by using $47.5 \%$ of corn bran, $47.5 \%$ of wheat bran, $4 \%$ of powder from melon seeds, sesame, pumpkinseeds and peanut; $0.5 \%$ of powder from cassava leaves and $0.5 \%$ of eggshell powder. The chemical composition showed that the multimistura presented high contents of carbohydrates $(74.24 \%)$ and proteins $(11.75 \%)$. The "multimistura" presented in its mineral composition $8.07 \mathrm{mg} \%$ of iron; $357.45 \mathrm{mg} \%$ of calcium; $235.10 \mathrm{mg} \%$ of magnesium; $677.65 \mathrm{mg} \%$ of potassium; $570.21 \mathrm{mg} \%$ of phosphorus and $7.02 \mathrm{mg} \%$ of sodium. The biological essay revealed that group I presented a body-weight $42 \%$ higher than groups II and III, and 37\% more than group IV. The food and protein intake were better presented by group I. The addition of multimistura did not affect the rat recovery.

Keywords: "multimistura"; malnutrition; Wistar rats; chemical composition.

\section{1 - INTRODUÇÃO}

A fome e a desnutrição no Brasil continuam sendo as principais causas de mortes e doenças de milhões de crianças. A Pastoral da Criança, organização de ação social da Conferência Nacional dos Bispos do Brasil (CNBB), em balanço referente a suas ações no primeiro trimestre do ano de 1999 em todo o Brasil, demonstrou um ligeiro aumento da desnutrição e da mortalidade infantil em alguns Estados brasileiros, especialmente Ceará e Paraiba. Comparando os dados de 1999 com os do mesmo período do ano anterior, entre as 450 mil crianças acompanhadas mensalmente pela Pastoral em todo o Nordeste, a desnutrição se manteve na casa dos 11,85\%, já no Ceará, a desnutrição aumentou de 14,75\% para $15,2 \%$ e, na Paraíba, de $13 \%$ para $15,2 \%$. As causas principais desses aumentos devem estar ligadas aos problemas advindos da seca que afetou a região [11].

${ }^{1 .}$ Recebido para publicação em 10/01/2003. Aceito para publicação em 01/12/2003 (001054).

2. Departamento de Tecnologia Química e de Alimentos, Centro de Tecnologia, Universidade Federal da Paraíba (DTBA/CT/UFPB), Campus I. João Pessoa. CEP-58.059-900. E-mail: msmadruga@uol.com.br.

3. Curso de Pós Graduação em Produtos Naturais e Sintéticos Bioativos do Laboratório de Tecnologia Farmacêutica/UFPB.

4. Departamento de Nutrição, Universidade Federal de Pernambuco (DN/ UFPE).

*A quem a correspondência deve ser enviada.
Uma das medidas adotadas para diminuir o quadro de desnutrição no Brasil está relacionada aos Programas de Suplementação Alimentar, nos quais se inclui a utilização de misturas à base de farelo de cereais, popularmente denominadas de "multimistura".

A utilização e os padrões de identidade e qualidade destas misturas à base de farelo de cereais foram regulamentados pela Agência Nacional de Vigilância Sanitária (ANVISA/MS), através da Resolução nº 53 em 15 de junho de 2000, publicada no DOU de 19/06/2000. Esta Resolução definiu a Mistura à Base de Farelo de Cereais como sendo "produto obtido pela secagem, torragem, moagem e mistura de ingredientes de origem vegetal, podendo ser adicionada de leite em pó" [7].

Anteriormente, BRANDÃO \& BRANDÃO [5] definiram a multimistura como sendo uma mistura de alimentos não convencionais que enriquecem a alimentação habitual em minerais e vitaminas, para se obter uma dieta balanceada, sem alteração dos hábitos alimentares.

Como em todo o Estado da Paraíba, a multimistura ou a mistura à base de farelo de cereais, tem sido amplamente divulgada pela Pastoral da Criança, e a sua utilização tem sido bastante questionada, motivando a realização de vários estudos no sentido de se determinar o valor nutritivo das diversas misturas $[4,8,17]$. 
No Hospital Universitário Lauro Wanderley (UFPB), o Programa de Alimentação Alternativa não utiliza este produto unicamente para casos graves de desnutrição, embora essa seja sua principal missão, mas também para patologias como: diabetes, hiperlipemia, constipação intestinal e em portadores de HIV.

Tendo em vista o crescente uso da multimistura no combate as diversas patologias, bem como a ausência de dados científicos sobre sua direta aplicação na recuperação de pessoas desnutridas, este trabalho teve como objetivo avaliar a influência de uma multimistura no combate à desnutrição em ratos machos Wistar, no que se refere ao crescimento e estado nutricional.

\section{2 - MATERIAIS E MÉTODOS}

\section{1 - Animais}

Foram utilizados 60 ratos machos da linhagem Wistar, provenientes da colônia do Biotério de Criação do Departamento de Nutrição da Universidade Federal de Pernambuco, desmamados aos 21 dias de idade, com pesos equilibrados $(\cong 50 \mathrm{~g})$ e mantidos segundo MERUSSE \& LAPICHIK [18]. Todos os animais receberam dieta aprotéica por 14 dias; ao final desse período, selecionaramse 12 ratos para constituir o Grupo 0 (aprotéico); os 48 restantes foram divididos em 4 grupos de 12 animais, que passaram a alimentar-se, por 28 dias, com diferentes dietas.

Durante todo o experimento, realizou-se, semanalmente, o controle do peso corporal e do consumo da ração dos animais, através de pesagens da ração oferecida e de sobras, para determinar-se, posteriormente, o Coeficiente de Eficiência Alimentar - CEA [12]. O registro dos dados realizou-se até que os ratos atingissem 63 dias de idade.

\section{2 - Dietas}

Foram preparados cinco tipos de dietas: Grupo 0 (Dieta Aprotéica); Grupo I (Dieta Controle-Caseína); Grupo II (Dieta Creche); Grupo III (Dieta Creche $+1,2 \mathrm{~g}$ de Multimistura); Grupo IV (Dieta Creche $+2,4 \mathrm{~g}$ de Multimistura). As dietas foram confeccionadas semanalmente, no Laboratório de Nutrição Experimental do Departamento de Nutrição da UFPE, e oferecidas diariamente aos animais, em quantidade suficiente para garantir o consumo ad libitum. Os teores de vitaminas, sais minerais, fibras e demais nutrientes foram equilibrados segundo as recomendações da AIN 93 para o rato [21]. Com exceção da dieta aprotéica, as demais dietas compuseram-se por $\pm 10 \%$ de proteína, que é a quantidade necessária para ratos em desenvolvimento. Na Tabela 1 está apresentada a composição das dietas utilizadas no experimento. Para a elaboração da dieta creche levou-se em consideração as necessidades dos ratos na fase de crescimento, utilizando-se como base uma dieta suplementada com $5 \mathrm{~g}$ de multimistura per capita, oferecida a crianças na faixa etária de 2 a 6 anos, em uma creche no município de João
Pessoa, baseada no inquérito recordatório realizado por profissionais do Departamento de Nutrição da Universidade Federal da Paraíba. Os constituintes desta dieta foram obtidos no mercado local. A dieta creche foi adicionada de dois níveis de multimistura, que corresponderam a $1,2 \mathrm{~g} / \%$ e $2,4 \mathrm{~g} / \%$.

A multimistura utilizada neste estudo teve a mesma constituição da oferecida a crianças desnutridas, pelo Setor de Puericultura do Hospital Universitário Lauro Wanderley (HULW) da UFPB, a qual continha em sua formulação: $47,5 \%$ de farelo de trigo; $47,5 \%$ de fubá de milho; 4\% (em quantidades proporcionais) de pó de sementes de melão, gergelim, abóbora e amendoim; 0,5\% de pó da folha de mandioca e $0,5 \%$ de pó da casca de ovo.

TABELA 1. Dados de Composição Química das dietas utilizadas na alimentação de ratos Wistar.

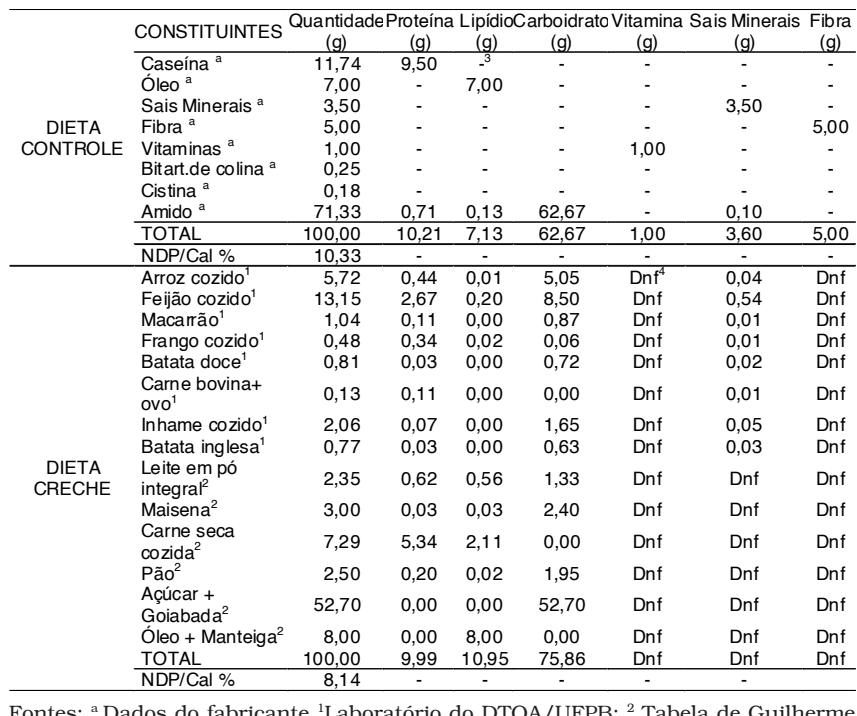

Fontes: a Dados do fabricante ${ }^{1}$ Laboratório do DTQA/UFPB; ${ }^{2}$ Tabela de Guilherme Franco [13]; ${ }^{3}(-)$ ausência ${ }^{4}$ Dnf - Dado não fornecido.

\section{3 - Análises da composição centesimal}

Na determinação da composição centesimal da multimistura foram utilizados os métodos preconizados pelo INSTITUTO ADOLFO LUTZ [14].

\section{4 - Análises de minerais}

Determinou-se o cálcio, o ferro, o magnésio, o fósforo, o sódio e o potássio. Para essas análises utilizouse a espectrometria de emissão atômica por Plasma indutivamente acoplado (ICP-AES), marca BAIRD, modelo ICP 2000, segundo ANGELUCCI \& MANTOVANI [2].

O preparo das amostras constou de destruição da matéria orgânica por incineração em mufla a $500^{\circ} \mathrm{C}$, seguida de adição de ácido nítrico concentrado e de evaporação até a secura em placa aquecedora (Coming, DC351). As cinzas obtidas foram diluídas em ácido nítrico a $2,5 \%$.

\section{5 - Análises microbiológicas}

Realizou-se a contagem total de bactérias mesófilas viáveis e de bolores e leveduras; a pesquisa do nú- 
mero mais provável (NMP) de coliformes totais e fecais e a ausência ou presença de Staphylococcus aureus. O tratamento das amostras e a metodologia utilizada para os ensaios estiveram amparados na Portaria no 451 de 19 de setembro de 1997, do Ministério da Agricultura, do Abastecimento e da Reforma Agrária [6].

\section{6 - Ensaios biológicos}

As rações foram avaliadas através do Coeficiente de Eficiência Alimentar [9].

\section{7 - Análises estatísticas} [24].

Foi elaborada através do Statistical Analysis System

\section{3 - RESULTADOS E DISCUSSÃO}

Na Tabela 2 estão apresentados os resultados da composição química e da multimistura e da ração creche. A multimistura foi rica no grupo dos carboidratos/ fibras, tendo teores menores de lipídios quando comparada a ração creche. Sabe-se que a composição básica da multimistura é farelo de trigo, de arroz e fubá, variando a proporção destes três farináceos de região para região do país. Alguns autores como MADRUGA \& CÂMARA [17], INSTITUTO DE TECNOLOGIA DE ALIMENTOS [15] e OLIVEIRA, FERNANDES \& BOAVENTURA [19], ao estudarem multimisturas de composições semelhantes a essa em questão, encontraram valores compatíveis com os resultados desta pesquisa.

TABELA 2. Composição química da multimistura e da ração creche

\begin{tabular}{lll}
\hline COMPONENTES QUÍMICOS & Multimistura & Ração Creche \\
\hline Cinzas $^{1}$ & $2,68^{*}$ & $2,90^{*}$ \\
Proteínas $^{1}$ & $11,75^{*}$ & $10,00^{*}$ \\
Lipídios $^{1}$ & $5,21^{*}$ & $10,95^{*}$ \\
Fibras $^{1}$ & $6,12^{\star}$ & $\mathrm{Nd}$ \\
Carboidratos $^{1}$ & $74,24^{*}$ & $75,86^{*}$ \\
\hline Ferro $^{2}$ & $8,07^{*}$ & $3,04^{*}$ \\
Cálcio $^{2}$ & $357,45^{*}$ & $73,00^{*}$ \\
Fósforo $^{2}$ & $570,21^{*}$ & $155,00^{*}$ \\
Magnésio $^{2}$ & $235,10^{*}$ & $52,90^{\star}$ \\
Sódio $^{2}$ & $7,02^{*}$ & $513,00^{*}$ \\
Potássio $^{2}$ & $677,65^{*}$ & $439,00^{*}$
\end{tabular}

${ }_{2}^{1} \mathrm{~g} / 100 \mathrm{~g}$

${ }^{2} \mathrm{mg} / 100 \mathrm{~g}$

3 carboidratos totais incluind
$*$ percentuais em base seca

A fibra alimentar foi um dos constituintes que se sobressaíram no valor nutritivo da multimistura, a qual apresentou um teor de 6,12\% neste produto. No entanto, sabe-se que a fibra interfere na utilização de minerais, pois, no complexo molecular da mesma, algumas substâncias podem agir como agentes quelantes de minerais.

Apesar de as fibras serem resistentes à hidrólise das enzimas digestivas, a microbiota do intestino grosso é capaz de fermentar parcialmente seus constituin- tes, resultando em produtos que podem alterar o metabolismo da flora intestinal, alguns processos metabólicos do intestino grosso e, principalmente, a absorção de ácidos graxos de cadeia curta, contribuindo, assim, para elevar o metabolismo energético [4].

Observou-se também que a multimistura é mais rica em minerais do que a ração creche, constituindo, aquela, uma excelente fonte de ferro, de cálcio e de magnésio, como também uma boa fonte de potássio e fósforo, além de apresentar baixas proporções de sódio.

Pelo fato de a multimistura ser um alimento utilizado na alimentação humana e por ser de fabricação artesanal, esta tem sido objeto de estudos envolvendo um melhor controle na qualidade e higiene do mesmo. Os resultados microbiológicos apresentados na Tabela 3 mostram que a multimistura estava própria para o consumo humano, considerando-se que todas as contagens apresentavam-se abaixo dos limites permitidos pela legislação [6].

TABELA 3. Qualidade microbiológica da multimistura.

\begin{tabular}{llll}
\multicolumn{1}{c}{ Microrganismos } & \multicolumn{1}{c}{ Unidades $^{1}$} & \multicolumn{1}{c}{ Multimistura } & \multicolumn{1}{c}{ Legislação $^{4}$} \\
Bactérias mesófilas & $\mathrm{UFC} / \mathrm{g}^{1}$ & $1 \times 10^{4}$ & - \\
Bolores e leveduras & $\mathrm{UFC/g}$ & $0,05 \times 10^{4}$ & $<1 \times 10^{4}$ \\
Coliformes totais & $\mathrm{NMP} / \mathrm{g}^{2}$ & 70 & - \\
Coliformes fecais & $\mathrm{NMP} / \mathrm{g}$ & Negativo & - \\
Staphyłococcus aureus & Aus/pres & \\
& & Ausente & $<6,0 \times 10^{2}$ \\
${ }^{1} \mathrm{UFC} / \mathrm{g}$ - unidade formadora de colônias por gramas; & \\
${ }^{2} \mathrm{NMP} / \mathrm{g}$ - número mais provável por gramas; & \\
${ }^{3}$ Aus = ausente, pres=presente; &
\end{tabular}

Comparando-se os resultados das análises microbiológicas com alguns trabalhos publicados, observou-se que as multimisturas estudadas por CARVALHO et al. [10], por AZEREDO [3] e por PRATES [20] também apresentavam qualidade microbiológica satisfatória. No entanto, SANTOS, SOUZA \& LIMA [22] ao avaliarem uma multimistura processada no setor de Puericultura de um Hospital Universitário-PB, destinada a três categorias de pacientes: crianças, idosos e aidéticos, observaram que as amostras encontravamse em condições higiênico-sanitárias insatisfatórias. Anteriormente, SANTOS, SOUZA \& PONTES [23] identificaram bolores e leveduras, sendo alguns produtores de micotoxinas, em uma multimistura distribuída por este mesmo Hospital, embora as amostras estivessem dentro dos parâmetros da legislação.

ANDRADE \& CARDONHA [1] relataram que, em uma multimistura produzida pela ATIVA-RN, a contagem de coliformes fecais, em 90\% das amostras, foi superior ao padrão estabelecido. A presença de bolores e leveduras foi constatada em níveis que variaram de $0,7 \times 10$ a $7,4 \times 10^{3}$ UFC/g de alimento, de acordo com os limites estabelecidos. Foi observada a presença de Salmonella spp. em 5\% das amostras e a ausência de $S$. aureus.

Os dados coletados da avaliação nutricional de perda e ganho de peso, ingestão alimentar, ingestão protéica e CEA, dos animais, estão apresentados na Tabela 4. 
Na Figura 1, estão apresentadas as curvas de crescimento ponderal dos animais. Observando os valores médios da perda de peso corporal dos animais, verificase que a perda de peso não diferiu entre os grupos, o que é considerado normal após a fase de desnutrição, sendo verificada uma perda média de 10,8g. Diferença significativa ocorreu no período da recuperação, durante o qual o Grupo Controle teve um ganho de peso acentuado sobre os demais grupos. O ganho de peso total foi estatisticamente diferente $(\mathrm{p}<0,05)$ entre o Grupo Controle e os demais. O do Grupo I foi 57\% maior em relação ao Grupo II; 58\% em relação ao Grupo III e 51\% em relação ao Grupo IV. Apesar de o Grupo IV ter obtido um maior ganho de peso em relação aos grupos II e III, isso não foi estatisticamente relevante neste estudo.

TABELA 4. Valores médios das perdas e ganhos de pesos corporais, ingestão alimentar, ingestão protéica e Coeficiente de Eficiência Alimentar (CEA) em função das diferentes dietas utilizadas.

\begin{tabular}{lccccc}
\hline \multirow{2}{*}{ GRUPOS } & \multicolumn{2}{c}{ PESO $(\mathrm{g})$} & \multicolumn{2}{c}{ INGESTÃO $(\mathrm{g})$} & \multirow{2}{*}{ CEA } \\
\cline { 2 - 4 } & Perda & Ganho & Alimentar & Proteína & \\
\hline Grupo I & $10,82^{\mathrm{a}}$ & $153,08^{\mathrm{a}}$ & $380,71^{\mathrm{a}}$ & $38,87^{\mathrm{a}}$ & $0,40^{\mathrm{ab}}$ \\
Grupo II & $10,82^{\mathrm{a}}$ & $97,39^{\mathrm{b}}$ & $226,67^{\mathrm{b}}$ & $22,64^{\mathrm{b}}$ & $0,43^{\mathrm{a}}$ \\
Grupo III & $10,38^{\mathrm{a}}$ & $96,76^{\mathrm{b}}$ & $247,27^{\mathrm{b}}$ & $24,70^{\mathrm{b}}$ & $0,39^{\mathrm{b}}$ \\
Grupo IV & $11,04^{\mathrm{a}}$ & $101,25^{\mathrm{b}}$ & $252,02^{\mathrm{b}}$ & $24,81^{\mathrm{b}}$ & $0,41^{\mathrm{b}}$ \\
\hline
\end{tabular}

Nas colunas, valores seguidos pela mesma letra não diferem estatisticamente entre si, pelo teste de Tukey, ao nivel de $5 \%$ de probabilidade.

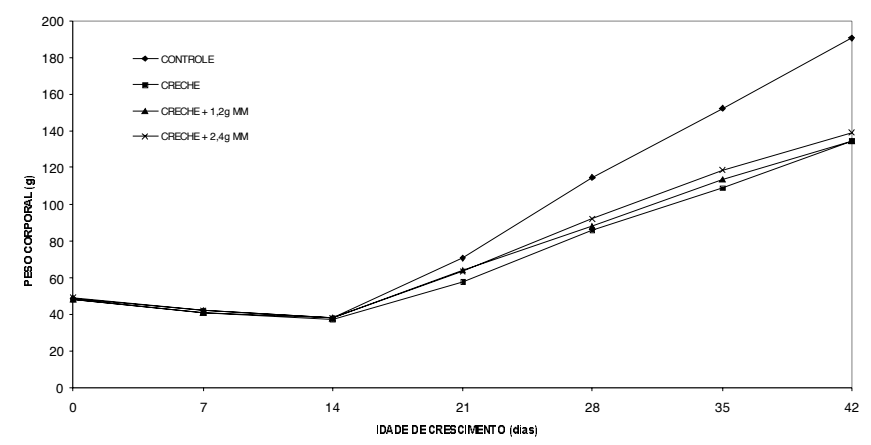

FIGURA 1. Curvas de evolução do peso corporal dos ratos por tratamento

Os resultados dos ensaios biológicos estão de acordo com as observações de JONG, STEINMUELLER \& LEAL [16] que demonstraram não haver diferença significativa no ganho de peso, no consumo alimentar e no CEA entre ratas desnutridas ingerindo dietas suplementadas ou não com multimistura. Segundo esses autores, no período de recuperação as respostas foram bastante semelhantes, indicando que, quando há alimento adequado, a presença ou ausência de multimistura não influencia no crescimento dos animais. BION et al. [4], realizando estudo semelhante com ratos machos, utilizando como dieta básica feijão + arroz, suplementada ou não com multimistura, durante os períodos de 28 e 112 dias, concluíram que os ratos observados a curto e em longo prazo, não apresentaram efeitos provocados pela multimistura em relação à curva ponderal. Os animais alimentados com caseína tiveram um melhor crescimento, isso devido a uma dieta que possuía um perfil de aminoácidos equilibrados e uma maior digestibilidade.

Os dados de ingestão alimentar total entre os grupos, ao final dos períodos ensaiados (Tabela 4), demonstraram que só o Grupo Controle apresentou diferença significativa em relação aos demais. A adição de multimistura não aumentou o consumo alimentar, o que poderia ser atribuído a palatabilidade da ração, fator de grande influência na ingestão de dietas pelos animais de laboratório [4].

Segundo DE LUCA et al. [12], a quantidade média de ração para rato situa-se na faixa de 12 a $15 \mathrm{~g}$ por dia. Considerando-se os quatro grupos estudados, apenas o Grupo I ingeriu a quantidade média recomendada de ração, ou seja, 13,6g por dia, enquanto que os Grupos II, III e IV consumiram quantidades inferiores, cujo valor médio foi de $8,6 \mathrm{~g}$ por dia.

Os valores do CEA ao final do período de recuperação indicaram melhores resultados para o Grupo II e foram estatisticamente diferentes dos Grupos III e IV. Esse resultado demonstrou que a proteína das rações foi tão bem aproveitada biologicamente quanto à proteína padrão de caseína (recomendada para o grupo em estudo), e que a dieta creche estava bem equilibrada nutricionalmente, refletindo a qualidade da dieta oferecida a crianças na faixa etária de 2 a 6 anos.

\section{4 - CONCLUSÃo}

Os resultados obtidos neste trabalho levam a concluir que a multimistura adicionada a uma dieta de uma creche não influenciou na recuperação ponderal de animais de laboratório.

\section{5 - REFERÊNCIAS BIBLIOGRÁFICAS}

[1] ANDRADE, A. S., CARDONHA, A. M. S. Análise microbiológica da multimistura In: CONGRESSO BRASILEIRO DE CIÊNCIA E TECNOLOGIA DE ALIMENTOS, 16,1998, Rio de Janeiro. Anais... Rio de Janeiro: SBCTA, 1998.

[2] ANGElUCCI, E., MANTOVANI, D.M.B. Minerais em alimentos: manual técnico. Campinas: ITAL/SBCTA, $1986.131 \mathrm{p}$.

[3] AZEREDO, V. B. Estudo das características químicas, nutricionais e microbiológicas da multimistura. SIMPÓSIO LATINO AMERICANO DE CIÊNCIA DE ALIMENTOS, 2, 1997, Campinas.

[4] BION, F. M., PESSOA, D. C. N. P., LAPA, M. A. G., CARVALHO, M. J. Uso de uma multimistura como suplementação alimentar: estudo em ratos. Arch Lat. Amer. Nutr. v.47, n.3, p. 242-247, 1997.

[5] BRANDÃO, T. T. C., BRANDÃO, R. F. Alimentação Alternativa. Brasília: INAN/Ministério da Saúde. 1996. 95p.

[6] BRASIL. Ministério da Agricultura, do Abastecimento e da Reforma Agrária. Portaria n. ${ }^{\circ} 451$ de 19 de setembro de 1997. Regulamento Técnico, Princípios Ge- 
rais para o Estabelecimento de Critérios e Padrões Microbiológicos para Alimentos e seus anexos I, II e III. Brasília, 1997.

[7] BRASIL. Ministério da Saúde. Secretaria Nacional de Vigilância Sanitária. Resolução - RDC n. ${ }^{\circ} 53$ de 15 de Junho de 2000. Regulamento Técnico para Fixação de Identidade e Qualidade de Mistura à Base de Farelo de Cereais. Brasília, 2000. 4p.

[8] CÂMARA, F. S., MADRUGA, M. S. Cyanic acid, Phytic acid, total tannin and aflatoxin contents of a Brazilian (Natal) multimistura preparation. Revista de Nutrição. v. 14, n.1, p.33-36, 2001.

[9] CAMPBELL, J. A. Method for determination of PER and NPR in Food and Nutrition Board. Evaluation of Protein Quality. Washington: Committee on Protein Quality, 1963. p.31-32.

[10] CARVAlhO, R. D. S., SANATANA, L. R. R., LiMA, M. G. C. Caracterização e estudo de estabilidade da multimistura. 1998. In: CONGRESSO BRASILEIRO DE CIÊNCIA E TECNOLOGIA DE ALIMENTOS, 16, 1998, Rio de Janeiro. Anais... Rio de Janeiro: SBCTA.

[11] CONFERENCIA NACIONAL DE BISPOS DO BRASIL. Pastoral da Criança. Tendência de queda da mortalidade infantil no país foi interrompida. Campanhas Pastoral da Criança e Tendência da Mortalidade 99. São Paulo, 1999.

[12] DE LUCA, R. R., ALEXANDRE, S. R., MARQUES, T. Manual para técnicos em bioterismo. São Paulo: Winner Graph, 1996. 259p.

[13] FRANCO, G. Tabela de Composição Química dos Alimentos. 3ed. São Paulo: Atheneu, 1997.301p.

[14] INSTITUTO ADOLFO LUTZ. Normas Analiticas do Instituto Adolfo Lutz: métodos químicos e físicos para análises de alimentos. 3.ed. São Paulo, 1985. 371p.

[15] InStituto DE TECNOLOGiA DE Alimentos. Avaliação química e nutricional de farinha composta. Campinas, 1995. 10p.

[16] JONG, E. V., STEINMUElleR, A., LEAL, S. Resposta da suplementação de dieta com multimistura na recupera- ção de ratos desnutridos. In: CONGRESSO BRASILEIRO DE CIÊNCIA E TECNOLOGIA DE ALIMENTOS, 26 , 1998, Rio de Janeiro. Anais... Rio de Janeiro: SBCTA.

[17] MADRUGA, M. S., CAMARA, F. S. The chemical composition of "Multimistura" as a food supplement. Food Chemistry, n.68, p.41-44, 2.000.

[18] MERUSSE, J. L. B., LAPICHIK, V. B. V. Instalações e equipamentos. In: COMISSÃO DE ENSINO DO COLÉGIO BRASILEIRO DE EXPERIMENTAÇÃO ANIMAL. Manual para técnicos em bioterismo. 2.ed. São Paulo: EPM, 1996. 259p.

[19] OLIVEIRA, E. M., FERNANDES, N. R. A., BOAVENTURA, G. T. Qualidade protéica da dieta consumida por crianças desnutridas do municipio de Quissamã e adicionada de alimentos não convencionais. Estudo em ratos. Niterói, 1997. Monografia (Graduação em Nutrição). Universidade Federal Fluminense.

[20] PRATES, A. C. M. Estudo do farelo de trigo, pó de folha de mandioca e pó de casca de ovo em crianças com risco de desnutrição. Recife, 1998. 60p. Dissertação (Mestrado em Saúde Pública). Universidade Federal de Pernambuco.

[21] REEVES, P. G., NIELSEN, F. H., FAHEY, G. C. AIN-93 Purified diets for laboratory rodents: final report of the American Institute of Nutrition Ad Hoc writing Committee on the reformulation of the AIN-76A rodent diet. J. Nutrition. v.123, n.10, p.939-1951, 1993.

[22] SANTOS, H. B., SOUSA, S., LIMA, A. W. O. Caracterização microbiana de multimisturas usadas como suplemento alimentar num Hospital Universitário. In: CONGRESSO BRASILEIRO DE ANÁLISES CLÍNICAS, 26, 1999, Goiânia. Resumos... Goiânia: SBAC.

[23] SANTOS, H. B., SOUSA, S., PONTES, Z. B. Identificação de bolores e leveduras isolados em multimistura. In: CONGRESSO BRASILEIRO DE CIÊNCIA E TECNOLOGIA DE ALIMENTOS, 16, 1998, Rio de Janeiro. Anais... Rio de Janeiro: SBCTA.

[24] SAS INSTITUTE. SAS user's guide: statistics. Cary, 1985. 956p. 